\title{
Canadian FSL Teacher Candidate Beliefs about Students with Learning Difficulties
}

\author{
Katy Arnett \\ St. Mary's College of Maryland, USA \\ Callie Mady \\ Nipissing University, North Bay, Ontario, Canada \\ Lin Muilenburg \\ St. Mary's College of Maryland, St. Mary’s City, MD, USA
}

\begin{abstract}
Through the lens of critical theory, and with consideration of research on the beliefs of teacher candidates and inclusion, this study considers the views of French Second Language pre-service teachers toward students with learning difficulties. This study reports on the results of two questionnaires, implemented prior to and following the participants' classroom practicum experiences, as a way to determine if and how experience and/or other personal demographic factors shaped their beliefs. Results indicated that personal experience with individuals with disabilities, along with the length of the practicum experience were reasons for more positive views towards this student population, which support new conceptualizations of teachers' work with students from different "cultures."
\end{abstract}

Index Terms - teacher candidates, inclusion, second language education, learning difficulties

\section{INTRODUCTION}

This particular study was conceived as a way to determine how teacher candidates ${ }^{1}$ in French Second Language (FSL) from across Canada viewed students with learning difficulties ${ }^{2}$ prior to and following their practicum experiences. Specifically, there was interest in seeing how future teachers felt about these students and if and how the teacher candidates' beliefs were responsive to pre-service coursework and/experiences, (e.g., Garmon, 2004, 2005; Mills \& Ballantyne, 2008; Peacock, 2001). It is the goal of the authors that in considering these specific data points, the FSL teacher education community might be able to open further discussions about the nature of the FSL teacher education curriculum in this second decade of the 21st century so that it can better respond to the needs of the changing populations in Canadian FSL classrooms. Outside of Canada, this issue has relevance for those who are facing questions about how to best respond to a variety of learner needs.

This study will consider the influence of particular experiences in shaping teacher candidate views, which would offer a new take on Garmon's (2005) assertion that pre-service teachers' prior experiences with students from different cultures and races influenced their receptiveness to working with students from those backgrounds by considering connections to learning difficulties and/or other disabilities in the backgrounds of the teacher candidates. Further, extending the previous work of the first two authors of this article (Arnett \& Mady, 2010), this inquiry will also use critical theory to explore the existing research relevant to this study, as well as the results uncovered in the analyses. Critical theory focuses on the ways in which dominant forces, people, policies, and/or philosophies come to oppress and/or discriminate against minority populations and the ways in which policies and practices come to be unjust in the first place (Willis, Montavon, Hall, Hunter, Burke, \& Herrera, 2008). Because this line of research is specifically focusing on a student population within the K-12 environment that holds minority status and how new teachers (powerholders) view this population, critical theory is particularly apt.

\section{LITERATURE REVIEW}

Broadly, there are three themes under consideration in this article: the educational experience of students with language-based difficulties in the FSL classroom, teacher candidate beliefs and perceptions, and the construct of "inclusive teaching". Second language teacher education is a fourth theme, but will be considered tangentially in the other areas.

\section{Students with Difficulties the FSL Classroom}

\footnotetext{
${ }^{1}$ Throughout this paper, we will use several terms to refer to the population of individuals planning to become teachers. Though the term "teacher candidate," is becoming preferential in Canada, the literature still refers to this group as "new teachers," "pre-service teachers" or "student teachers."

${ }^{2}$ Though "disability" is the more common term, we have opted for a more neutral term. When "disability" appears in this article, it is to specifically reference the construct.
} 
The notion of "suitability" of FSL for students with learning difficulties has been questioned and debated since the inception of the French immersion program in Canada (see Genesee, 2007 \& Mannavaryan, 2003, for reviews). This debate continues in spite of the fact that there has been more positive evidence than negative evidence that French immersion can be of benefit to students with uneasy relationships with language, in general (Genesee, 2007).

A case study by Mady and Arnett (2009) points out that it may be possible that some decisions about struggling students' continuation in French immersion are not being informed by the research on students' potential for success in French immersion, but rather by individual principal beliefs. In this case study, the principal of the school was reluctant to let a student with documented language-based learning difficulties continue in French immersion because the principal viewed it as an "enrichment" program and as such, support would not be provided. In this instance, though the school board (in Ontario) did not have an explicit policy of banning students with difficulties from the classroom experience, the personal beliefs of the principal held much power in the situation. In a related inquiry, Wise (2011) corroborated the extent to which students with difficulties were denied access to support in the French immersion programs, pointing out how funding formulas worked to perpetuate the inequities of support for both FSL and special education, showing yet another power influence.

For many years, the notion of suitability of FSL study for students with difficulties was not really considered in the context of the other FSL program options in Canada. Since the start of the new millennium, there have been some publications that have endeavored to explore the question in the context of core French ${ }^{3}$. Research by Arnett (2003, 2008, 2010) has shown that many of the teaching strategies commonly recommended for students with learning difficulties and other special education needs are highly congruent with the teaching strategies that inform good FSL instruction, at least in the core French context. These findings have directly countered a seemingly persistent idea in the research literature and general teaching corps that the needs of students with difficulties are inherently incompatible with the elements of good second language teaching and as such, these students should not be a part of the learning experience (e.g., Calman \& Daniel, 1998; Mannavaryan, 2002). Admittedly, though, there have yet to be any studies that measure the learning of students with difficulties in the FSL context, and this is a clearly needed research area.

Beliefs/Attitudes/Perceptions of teacher candidates in second language education

Arnett and Turnbull (2007) proposed that a synthesis of Ajzen's (1991) theory of planned behavior with Kennedy and Kennedy's (1996) extrapolation of Ajzen's work was a useful mechanism for delineating teachers' beliefs, attitudes and pedagogical knowledge, as all three tended to be conflated in research considering how teachers "viewed" a classroom or circumstance. Ajzen (1991) contends one's perceptions of what those holding positions of power believe about the matter at hand (i.e., as evidenced through the individual's interpretation of a curriculum or policy document, perhaps), along with the individual's perception of the degree of power he/she holds over the application of any knowledge or even a policy, work to inform beliefs. Thus, under Ajzen's work, what one believes, in general, about an issue is framed through the individual's perception of how those in power are likely to view the situation and the extent to which the individual in the situation feels that he/she has personal power to enact change. These two elements of Ajzen's theory provide a solid complement to the central tenet of critical theory.

Yet, Kennedy and Kennedy (1996) critiqued Azjen's conceptions of beliefs and attitudes as too static and narrow. In Arnett and Turnbull (2007), it was proposed that studies of second language teacher beliefs systems needed to consider other ways in which the knowledge informing the beliefs was created. They argued that there must also be some consideration of teachers' past experiences in the classroom (as both student and teacher), which is often referred to as the "apprenticeship of observation" (Johnson, 1999; Lortie, 1975) and teachers' personal experiences. As Arnett and Turnbull (2007) pointed out, this does engender a "messier" conception of teacher beliefs, attitudes, and perceptions, but perhaps more accurately captures the various nuances of the construct (Pajares, 1992). In this study, the instrument did include questions that focused on all of these areas - beliefs, attitudes, prior sociolinguistic and cultural experiences, depth of the apprenticeship of observation, and awareness of political constraints.

Research on initial teacher education that has employed the lens of critical theory has clearly revealed that individuals preparing to become teachers often already possess beliefs and views that speak to enforcing the current social and power structure at work in schools (Bartolomé, 2004; Friere, 1998). In other words, for teacher candidates, K-12 students who represent challenges to the status quo (i.e., students with learning difficulties) may be at risk in the classrooms of these individuals because of the ways in which the teacher candidates already view the social order. It was for this reason that this study focused on the pre-service level; in considering their views at the entry point of the career, there could be value in seeing what sort of belief systems and experiences could influence their practice.

\section{Inclusive Teaching}

Woven within and across the other two themes in this study is a consideration of the construct of "inclusive teaching," the idea that teachers need to structure and facilitate their learning in such a way to meet as many needs as possible within the classroom community - and that students across all ranges of the learning spectrum should be a part of the classroom. Inclusive education has been a political, practical, and philosophical focus for the last fifteen years, largely because of changes in the conceptions and premises of special education.

\footnotetext{
${ }^{3}$ Core French is an FSL program in which students study FSL as a subject for brief periods in their weekly timetable.
} 
While there are still mixed reviews on the success of inclusive teaching practices (Hutchinson \& Martin, 2012; Jordan, 2007), it is predicated on the premise that students with diverse learning needs are expected to be fully involved in the life and learning of the classroom community, even if such involvement is only possible through pedagogical accommodations and/or curricular modifications. When designing this study, the prior work of the authors in the areas of students with difficulties in FSL pointed to questions about whether these student populations should have access to this learning opportunity (i.e., mainstreaming), not just whether they could benefit from instruction through targeted instruction (inclusion) (Mastropieri \& Scruggs, 2010). Thus, even though Canadian school board policies, provincial and federal laws, and even federal initiatives have focused on inclusive teaching for diverse student populations, mainstreaming was also an element of consideration. There were, therefore, questions in the instrument that addressed thoughts about access to the FSL community (mainstreaming) and then teaching practices for meeting diverse learner needs (inclusion).

Jordan, Lindsay, and Stanovich (1997) found that when teachers held less positive views of students with special education needs, there were fewer attempts to ensure that the included student benefitted from the educational experience and that the teacher interacted with the included students in a "less academic way." Applying the lens of critical theory, these results show the extent to which belief systems can hold power over a student's educational experience and perhaps perpetuate inequities that exist; in considering how teacher candidates view certain student populations, it may be possible to predict where some students may fail to receive appropriate support in the classroom.

\section{Methodology}

This survey study used an online mechanism for collecting responses to a questionnaire, with each response period lasting approximately three weeks. The larger study also included phone interviews with several participants and questions about English Learners (i.e., Allophone students), but those data are not being considered at the present time.

\section{Recruitment}

Following approval from the authors' institutions, Author 1 led the participant recruitment. Author 1 contacted 28 FSL teacher education program heads across Canada, requesting that they share the link to our questionnaire with their candidates, where they would then choose to participate in the research. Approximately 6 months after the participants completed the questionnaire, they completed a post-questionnaire.

\section{The instrument}

The questionnaire followed the structure and to an extent, the content, of the questionnaire developed by Lapkin, MacFarlane, and Vandergrift (2006) to determine the perceptions and concerns of active FSL classroom teachers. Because of the initial goals of the research, the questionnaire was implemented at two points during the academic year-in late September/early October, prior to any sort of practicum experience, and in late April/early May, when candidates were nearing completion of their programs.

The pre-questionnaire included 11 questions pertaining to participants' demographic information; eighteen Likertscale statements, which asked participants to self-report the extent to which they agreed with certain statements about including students with learning difficulties in FSL programs; and four open-ended questions for participants to offer additional comments. The latter two sections served as the post-questionnaire. As self-reports of belief/perceptions are subject to the "halo effect," it is possible that some of our findings may not reflect the participants' true views at all times; this is why the larger study included an interview component.

\section{Participants}

Though the respondents to the post-questionnaire were drawn from the pool of respondents to pre-questionnaire, for the purpose of this study, the participant pools will be treated as two distinct groups because the results across the questionnaires were not compared in this current analysis.

\section{Pre-questionnaire participants.}

Tables 1 and 2 provide overviews of the demographic backgrounds of the participants who responded to the first questionnaire, considering their gender, teacher education and internship experience, and familial contact with disability. It should be noted that the male-female ratio in the study is higher than what has been found in the field, with women accounting for 73.6 percent of the teaching population in Canada (Statistics Canada, 2006). One participant indicated having Irlen Syndrome, which affects the processing of visual information, thereby influencing how the individual works with any sort of printed or imaged-based text. Upon completion of the credentialing programs, 15 participants $(19.2 \%)$ would be qualified to teach at the Primary (K-3) level, $28(35.9 \%)$ at the Junior (4-6) level, $10(12.8 \%)$ at the Intermediate (7-10) level, and 25 (32.1\%) at the Senior (11-12) level. 
TABLE 1

BASIC DESCRIPTION OF PRE-PRACTICUM QUESTIONNAIRE PARTICIPANTS

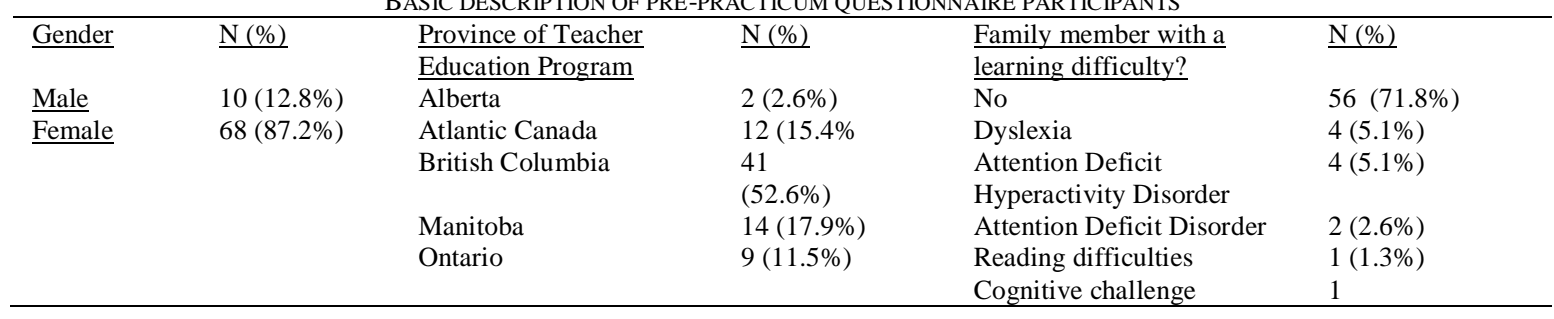

TABLE 2

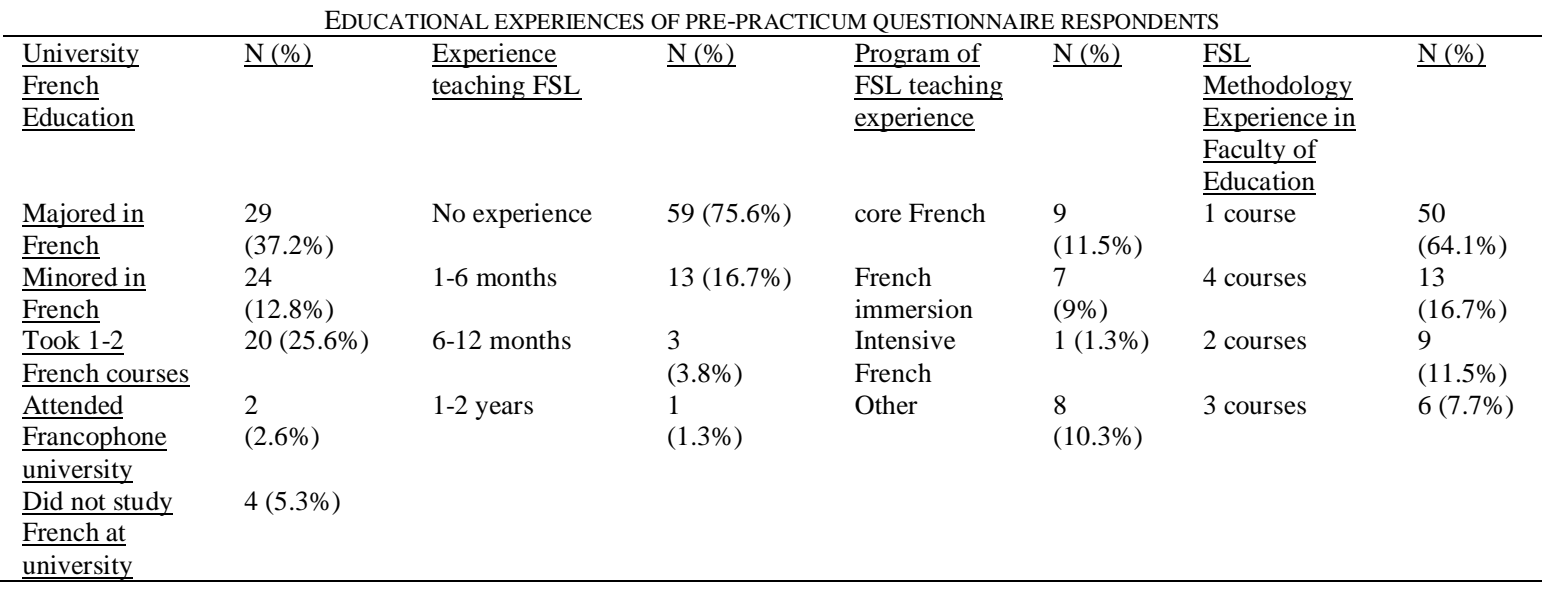

Post-practicum questionnaire participants.

There were 51 responses to the post-questionnaire, which represented a decline of 27 participants from the prequestionnaire sample. 48 of the 51 had also responded to the pre-questionnaire. Tables 3 and 4 provide the demographic background of these participants. Also, at the time the post-practicum questionnaire was administered, most participants were less than a month from the end of their program and were in a position to describe their experiences during the year. Thus, Table 4 also includes information about the participants' student teaching experiences. The participant with Irlen Syndrome also completed the questionnaire, but no additional data about experiences with disabilities were included in the post-practicum questionnaire. Questions relevant to these experiences should be included in future versions of this research.

TABLE 3

BASIC DESCRIPTION OF POST-PRACTICUM QUESTIONNAIRE PARTICIPANTS

\begin{tabular}{|c|c|c|c|}
\hline Gender & $\underline{\mathrm{N}(\%)}$ & Province of Teacher Education Program & $\underline{\mathrm{N}(\%)}$ \\
\hline Male & $5(9.9 \%)$ & Alberta & $2(4.2 \%)$ \\
\hline \multirow[t]{4}{*}{ Female } & $43(90.1 \%)$ & Atlantic Canada & $7(14.6 \%)$ \\
\hline & & British Columbia & $23(48 \%)$ \\
\hline & & Manitoba & $7(14.6$ \\
\hline & & Ontario & $9(18.8 \%)$ \\
\hline
\end{tabular}


TABLE 4

POST-PRACTICUM QUESTIONNAIRE RESULTS ON EDUCATIONAL AND TEACHING EXPERIENCE WITH FSL

\begin{tabular}{|c|c|c|c|c|c|c|c|c|c|c|c|}
\hline $\begin{array}{l}\frac{\text { on }}{\text { Majore }} \\
\frac{\text { d in }}{\text { French }}\end{array}$ & $\begin{array}{l}17 \\
(35.4 \%)\end{array}$ & $\begin{array}{l}\text { No } \\
\text { experience }\end{array}$ & $\begin{array}{l}37 \\
(77.1 \%)\end{array}$ & $\begin{array}{l}\underline{\mathrm{e}} \\
\text { core } \\
\text { French }\end{array}$ & $\begin{array}{l}4 \\
(8.3 \%)\end{array}$ & $\frac{\text { year? }}{\text { Yes }}$ & $\begin{array}{l}36 \\
(75 \%)\end{array}$ & $\begin{array}{l}\text { core } \\
\text { French }\end{array}$ & $\begin{array}{l}28 \\
(58.3 \%)\end{array}$ & 2 weeks & $7(14.6 \%)$ \\
\hline $\begin{array}{l}\frac{\text { Minore }}{\text { din }} \\
\text { French }\end{array}$ & $\begin{array}{l}15 \\
(31.3 \%)\end{array}$ & $1-6$ months & $6(12.5 \%)$ & $\begin{array}{l}\text { French } \\
\text { immersio } \\
\text { n }\end{array}$ & $\begin{array}{l}3 \\
(6.3 \%)\end{array}$ & No & $\begin{array}{l}11 \\
(22.9 \%)\end{array}$ & $\begin{array}{l}\text { French } \\
\text { immersi } \\
\text { on }\end{array}$ & $16(33 \%)$ & 4 weeks & $6(12.5 \%)$ \\
\hline $\begin{array}{l}\text { Took 1- } \\
\frac{2}{\text { French }} \\
\text { courses }\end{array}$ & $\begin{array}{l}1 \\
(2.1 \%)\end{array}$ & 6-12 months & $2(4.2 \%)$ & $\begin{array}{l}\text { Intensive } \\
\text { French }\end{array}$ & $\begin{array}{l}1 \\
(2.1 \%)\end{array}$ & & & $\begin{array}{l}\text { Intensive } \\
\text { French }\end{array}$ & $24.2 \%)$ & 5 weeks & $\begin{array}{l}3 \\
(6.3 \%)\end{array}$ \\
\hline $\begin{array}{l}\frac{\text { Attende }}{\text { dit }} \\
\text { Francop } \\
\underline{\text { hone }} \\
\text { universi }\end{array}$ & $\begin{array}{l}2 \\
(4.2 \%)\end{array}$ & $1-2$ years & $1(2.1 \%)$ & Other & $\begin{array}{l}5 \\
(10.4 \%)\end{array}$ & & & & & 6 weeks & $9(18.8)$ \\
\hline 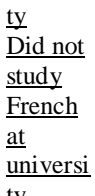 & $3(6.3 \%)$ & $\begin{array}{l}\text { More than } 5 \\
\text { years }\end{array}$ & $1(2.1 \%)$ & & & & & & & 7 weeks & $1(2.1 \%)$ \\
\hline 피 & & & & & & & & & & $\begin{array}{l}8 \text { weeks } \\
\text { Longer }\end{array}$ & $\begin{array}{l}3(6.3 \%) \\
10 \\
(20.8 \%)\end{array}$ \\
\hline
\end{tabular}

\section{RESULTS AND ANALYSIS}

The data from both questionnaires were analysed using SPSS 18.0. Descriptive statistics were generated for each quantitative item in the surveys. Relationships among the variables were examined using correlation, regression, and ANOVA. For all tests of statistical significance in this research study, an alpha level of .05 was used. As statistical analyses comparing the two questionnaires directly to each other did not produce any results of significance, this analysis will consider the questionnaires as two different data sets.

The results presented in this section will focus on the questions that required the participants to indicate their level of agreement with 15 (Questionnaire 1) or 18 statements (Questionnaire 2) about the student populations' presence in the classroom and in the case of the post-practicum questionnaire, the perceived influences on their belief systems. The ratings on the 5-point Likert scale were as follows: $1=$ strongly agree; $2=$ agree; $3=$ neutral; $4=$ disagree, $5=$ strongly disagree.

\section{Pre-practicum Questionnaire}

Table 5 summarizes the average rating given by participants to questions about their beliefs pertaining to the presence/educational experience of students with learning difficulties in FSL classrooms near the start of the academic year. The results are presented in rank-order, from greatest to least agreement. Four statements (Q4, Q9, Q10, Q11) had 77 responses, one statement (Q18) had 76 responses, and the remaining 13 questions had 78 responses. 
TABLE 5

MEANS FOR LD BELIEF ITEMS, RANK-ORDERED FROM GREATEST TO LEAST AGREEMENT

\begin{tabular}{|c|c|c|}
\hline & $\underline{\text { Mean }}$ & $\underline{\mathrm{SD}}$ \\
\hline 14. All students should have the opportunity to be part of Extended French, where available. & 1.63 & .605 \\
\hline 13. All students should have the opportunity to be part of French Immersion, where available. & 1.63 & 667 \\
\hline 6. To fully include students with learning difficulties, I must invest more planning time. & 1.63 & .913 \\
\hline 15. All students should have the opportunity to be part of Intensive French, where available. & 1.69 & .708 \\
\hline 1. I believe that students with learning difficulties should be included in core French. & 1.71 & .667 \\
\hline 12. All students should have the opportunity to be a part of Core French, where available. & 1.87 & 1.061 \\
\hline 2. I believe that students with learning difficulties should be included in French immersion, where available. & 2.01 & .830 \\
\hline 18. I believe that my teaching style naturally addresses a wide range of learner needs. & 2.13 & 680 \\
\hline 3. I believe that students with learning difficulties should be included in extended French, where available. & 2.19 & 1.045 \\
\hline 4. I believe that students with learning difficulties should be included in Intensive French, where available. & 2.31 & 1.029 \\
\hline 16. The curriculum for core French acknowledges and allows for a wide range of learner needs. & 2.36 & 1.081 \\
\hline 5. I believe the parents of students with learning difficulties support their children learning French. & 2.49 & 1.029 \\
\hline $\begin{array}{l}\text { 9. The strategies needed to respond to effectively support students with learning difficulties' needs are consistent with the } \\
\text { strategies I use to teach French. }\end{array}$ & 2.68 & .966 \\
\hline 7. There are occasions when a student with learning difficulties should be exempt from learning French. & 2.78 & 1.355 \\
\hline $\begin{array}{l}\text { 17. The curricular demands of a core French classroom are structured in a way that makes it hard to address a wide range of } \\
\text { learner needs. }\end{array}$ & 3.17 & .959 \\
\hline 11. The suggested accommodations for students with IEPs are incompatible with the goals and expectations of core French. & 3.49 & .968 \\
\hline 10. The suggested accommodations for students with IEPs are incompatible with my teaching style. & 3.40 & .936 \\
\hline $\begin{array}{l}\text { 8. The presence of students with learning difficulties has an unfavourable impact on the learning potential of the other } \\
\text { students in the class }\end{array}$ & 3.99 & .875 \\
\hline
\end{tabular}

A series of ANOVAs was conducted using these 18 items from the questionnaire as dependent variables and the demographic items as independent variables. The statistically significant relationships that emerged from this analysis will be presented next. First, though there was a small number of participants who reported having a family member with a learning difficulty $(\mathrm{N}=12)$, for three of the four questions which asked about whether students with learning difficulties should be included in various French programs, the mean differences were statistically significant when comparing participants who did and did not have family members with LD. This information is shown in Table 6 . The difference between the groups for the comparable question about the core French program was not statistically significant.

TABLE 6

MEAN COMPARISONS BETWEEN RESPONDENTS WHO DO AND DO NOT HAVE FAMILY MEMBERS WITH LD

\begin{tabular}{|c|c|c|c|c|}
\hline & $\begin{array}{l}\frac{M(S D) \text { for }}{\text { respondents with }} \\
\frac{\text { LD in their family }}{(N=12)}\end{array}$ & $\begin{array}{l}\frac{M(S D) \text { for }}{\text { respondents without }} \\
\underline{\text { LD in their family }} \\
\underline{(N=65)}\end{array}$ & $\begin{array}{l}\text { Mean } \\
\text { difference }\end{array}$ & Eta squared \\
\hline $\begin{array}{l}\text { Q2. I believe that students with learning } \\
\text { difficulties should be included in French } \\
\text { immersion, where available }\end{array}$ & $1.42(0.52)$ & $2.09(0.81)$ & $0.67 *$ & .094 \\
\hline $\begin{array}{l}\text { I believe that students with learning } \\
\text { difficulties should be included in extended } \\
\text { French, where available }\end{array}$ & $1.42(0.52)$ & $2.32(1.06)$ & $0.90 * *$ & .100 \\
\hline $\begin{array}{l}\text { Q4 I believe that students with learning } \\
\text { difficulties should be included in Intensive } \\
\text { French, where available }\end{array}$ & $1.67(1.16)$ & $2.41(0.96)$ & $0.74 *$ & .071 \\
\hline
\end{tabular}

When considering responses to the statement, "I believe students with LD should be included in core French," the mean differences were statistically significant when comparing the participants who reported previous teaching experiences $(N=13)$ to those who did not have prior teaching experiences $(N=15)$. The former group reported an average response of 2.15, which was in the range between "Agree," and "Neutral," while the later group reported an average response of 1.59, which was in the range between "Strongly Agree" and "Agree." ANOVA analyses revealed $p$ $=0.013$, with an Eta square of .137 .

Question 16 in this group asked participants about the extent to which they believed the curriculum of the core French program accounted for a wide range of learner needs. Again, previous teaching experience influenced the views of the participants. The average response of those with prior teaching experience was 2.54 , which is just over halfway between "Agree" and the neutral response. Those with no previous teaching experience recorded an average response of 2.22, which was closer to the "Agree" response. The ANOVA analysis revealed $p=0.038$, with an Eta square of .108.

Again, following the Likert-scale question, participants were offered an opportunity to elaborate on the specific strategies they would use to support the needs of students with LD in their classes; 15 participants accepted this opportunity. These participants offered a total of 44 different suggestions, and the five most frequent responses to this question are included here. Six participants suggested three strategies: adapting the lesson (i.e., "adapt it to them"), offering individual help (i.e., "one-on-one help"), and providing visual support (i.e., "use of visual). Three suggestions 
each had six respondents: providing visual support, adapting the lesson and offering individual help: "use of visual, oneon-one help, and adapt it to them" were some of the quotes.

Finally, the last question on the questionnaire provided the participants with the opportunity to add any additional information regarding the inclusion of students with LDs in FSL classes. 16 participants accepted this opportunity, and there were two ideas/points that were made by multiple participants. First, five participants focused on the broad ideas of inclusion in their remarks, which was not surprising given the stem of the prompt. Some of these comments included "If we support inclusion in English classrooms than we should support inclusion in French classes as well," and "Inclusion is important to success I've learned... I definitely think we should give it a go!" Twice, there were comments about inclusion being a student-specific experience, as evidenced by a remark like, "Each approach will depend on each individual student and should not be generalized."

\section{Post-practicum Questionnaire}

\section{Beliefs and attitudes.}

Table 7 summarizes the average score given by participants to questions about their beliefs pertaining to the presence/educational experience of students with learning difficulties in FSL classrooms. The results are presented in rank-order, from greatest to least agreement. All statements for this question recorded 51 responses.

TABLE 7

MEANS FOR LD BELIEF ITEMS, RANK-ORDERED FROM GREATEST TO LEAST AGREEMENT

\begin{tabular}{|c|c|c|}
\hline & Mean & $\underline{\mathrm{SD}}$ \\
\hline 6. To fully include students with learning difficulties, I must invest more planning time. & 1.37 & .848 \\
\hline 14. All students should have the opportunity to be part of Extended French, where available. & 1.43 & 1.005 \\
\hline 15. All students should have the opportunity to be part of Intensive French, where available. & 1.45 & 1.045 \\
\hline 12. All students should have the opportunity to be a part of Core French, where available. & 1.53 & 1.206 \\
\hline 2. I believe that students with learning difficulties should be included in French immersion, where available. & 1.53 & 1.102 \\
\hline 18. I believe that my teaching style naturally addresses a wide range of learner needs. & 1.82 & 1.161 \\
\hline $\begin{array}{l}\text { 9. The strategies needed to respond to effectively support students with learning difficulties' needs are consistent } \\
\text { with the strategies I use to teach French. }\end{array}$ & 1.84 & 1.138 \\
\hline 16. The curriculum for core French acknowledges and allows for a wide range of learner needs. & 1.84 & 1.332 \\
\hline 5. I believe the parents of students with learning difficulties support their children learning French. & 2.06 & 1.256 \\
\hline 10. The suggested accommodations for students with IEPs are incompatible with my teaching style. & 3.25 & 1.647 \\
\hline $\begin{array}{l}\text { 8. The presence of students with learning difficulties has an unfavourable impact on the learning potential of the } \\
\text { other students in the class }\end{array}$ & 3.33 & 1.807 \\
\hline
\end{tabular}

The responses to the value statements about participants' beliefs about students with learning difficulties in the FSL classroom were analyzed in relation to the participants' self-reported practica experiences and perceptions of changes in their opinions about including students with learning difficulties in FSL classrooms. ANOVA analyses revealed areas of statistical significance in the mean differences for two questions about their beliefs about inclusion in FSL for students with learning difficulties.

Participants who self-reported no change in their opinions disagreed more strongly with two statements than did the participants who did report a change in their opinions. First, the "no opinion change" group disagreed more strongly with the statement, "The suggested accommodations for students with IEPs are incompatible with my teaching style" (Opinion Change $=3.42$; No Opinion Change $=4.03 ; p=0.046$; Eta square $=0.09$ ). Second, the same group of participants disagreed more strongly with the statement, "The suggested accommodations for students with IEPs are incompatible with the goals and expectations of core French" (Opinion Change $=3.33$; No Opinion Change $=4.00 ; p=$ 0.024 ; Eta square $=0.12$ )

There were no findings of statistical significance when the type of participants' practicum experiences was considered in relation to their agreement or disagreement with the various value statements (FSL or non-FSL context or type of FSL program).

Regression analyses were used to determine if the length of the participants' practicum experience in the FSL classroom were an influence on any of their belief statements. The average practicum experience lasted for 6.2 weeks, and there were three statements with statistical significance. First, it was found that the longer the practicum experience, the more strongly participants agreed with the statement, "I believe parents of students with learning difficulties support their children learning French" (Mean response $=2.06 ; \mathrm{R}=-0.015 ; p=0.015$ ). Second, it was found that the longer the practicum experience, the more strongly participants agreed with the statement, "The strategies needed to effectively

\footnotetext{
${ }^{4}$ IEP stands for Individualized Education Program. An IEP is a document that establishes, formally, a special education need that must be supported in school. It is a legally binding document.
} 
support students with learning difficulties are consistent with the strategies I use to teach French" (Mean response 1.84; $\mathrm{R}=-0.361 ; p=0.020)$. Finally, it was found that the longer the practicum experience, the more strongly participants agreed with the statement, "All students should have the opportunity to be part of Intensive French, where available"

(Mean response $=1.45 ; \mathrm{R}=-.311 ; p=0.048$ ).

Perceptions of influences on beliefs/attitudes.

The participants were asked to rate the extent to which they felt certain factors influenced their beliefs and attitudes towards students with LD. The results are presented from greatest to least agreement. For this group of questions, the average number of responses was 43 , which is 8 less than the group who responded to the questions about the belief statements. The responses were marked on a 3-point Likert scale, with " 1 " indicating "strong influence," "2" indicating "some influence," and " 3 " indicating "no influence." As Table 8 indicates, all variables, on average, exerted some degree of influence. It appears that the stronger influences on the participants' beliefs/attitudes were internal states, rather than outside forces. The first "outside" source mentioned as an influence is "research," which ranked sixth.

TABLE 8

MEANS FOR LD INFLUENCE ITEMS RANK-ORDERED FROM GREATEST TO LEAST INFLUENCE.

8. Your own understanding of student's learning needs.

9. Your own familiarity with inclusive teaching practices/principles

6. My learning in FSL methodology class

7. Your own assessment of student's ability to succeed.

12. Your own assessment of your ability to accommodate.

5. Findings of research

10. Your own understanding of special education rules and protocols

14. Your own assessment of the benefits of French for students with learning difficulties.

1. Opinion of parents.

3. Opinion of the school principal.

11. Your own assessment of the student's need to focus on other subjects.

4. Availability of resources.

13. Your own assessment of how the inclusion of students with learning difficulties will impact the class.

2. Opinion of my colleagues.

\begin{tabular}{ll}
$\frac{\text { Mean }}{1.33}$ & $\frac{\text { SD }}{.474}$ \\
1.33 & .474 \\
1.40 & .495 \\
1.42 & .545 \\
1.49 & .592 \\
1.51 & .506 \\
1.56 & .590 \\
1.60 & .587 \\
1.63 & .655 \\
1.65 & .529 \\
1.69 & .643 \\
1.74 & .621 \\
1.74 & .693 \\
2.00 & .584 \\
\hline
\end{tabular}

The relationship between the participants' perceptions about sources of influence on their beliefs about students with LD in the FSL classroom and the participants' self-reported practicum experiences and perceptions of changes in their belief systems were also compared. The mean differences revealed four areas of statistical significance. First, those participants who had completed a practicum in an FSL environment were more influenced of their own assessment of the benefits of French for students with learning difficulties than those who did not complete a practicum in French (Opinion change $=1.48 ;$ No Opinion Change $=2.00 ; p=0.02$; Eta square $=0.13$ ). Second, participants who did report a change in their beliefs/attitudes towards students with learning difficulties were more influenced by the opinion of their colleagues than those who reported no change (Opinion change $=1.64$; No Opinion Change $=2.13 ; p=0.014$; Eta square $=0.14$ ). Within the narrative comments gathered through some questions at the end, it appeared that several participants reported no change in their positions because, either in their program or in their practica, they did not address/encounter students with learning difficulties. The narrative responses also included four comments about how the students with learning difficulties in their practicum classrooms confirmed already existing views. Three of those comments indicated that the initial and subsequent views were positive, and one indicated that the initial and subsequent views were negative.

For the other two areas of statistical significance, it appeared that the context in which the participants completed their practica had an influence on the factors of perceived influence. First, those participants who had a singular practicum in FSL (in any of the FSL programs) were more influenced by their personal assessment of the students' needs to focus on other subjects than those candidates who either had no practicum experience in FSL or experiences in multiple FSL programs (Core French = 1.50; Immersion/Extended/Intensive French = 1.50; Multiple Programs = 2.20; No Practicum Experience $=2.00 ; p=0.047$; Eta square $=0.19$ ). Next, the participants who again had a single practicum experience in any of the FSL programs were more influenced by their personal assessments of the benefits of French for students with learning difficulties than were participants who either had no practicum experience in an FSL classroom or multiple practica in an FSL classroom (Core French $=1.35$; Immersion/Extended/Intensive French = 1.43; Multiple Programs $=2.00 ;$ No Practicum Experience $=2.00 ; \mathrm{p}=0.007 ;$ Eta square $=0.27$. The duration of the practicum did not have any statistically significant findings for the influence items.

\section{DisCUSSION AND CONCLUSIONS}

As mentioned in the introduction, Garmon (2005) proposed that teacher candidates' attitudes and beliefs towards students from racial backgrounds different from their own were influenced by their overall personal dispositions and collective experiences. In a prior work, Garmon (2004) had outlined the three types of experiences critical to helping pre-service teachers work with diverse populations: intercultural experiences (where they had direct interaction with individuals who were from different cultures), educational experiences (where they had coursework, field experiences, and opportunities to reflect about issues related to diversity), and finally, support experiences in which the teacher 
candidates have the opportunity to ask questions and engage in "sensitive" dialogues with peers and teacher educators regarding the elements of diversity that are under consideration. In this study, educational and intercultural experiences (framed through the culture of "disability") were featured.

There was some limited evidence that personal experience with a learning difficulty did impact the views of the candidates on some questions that considered the presence of students with learning difficulties in the FSL classroom. While this was not a consistent trend within the data, the limited results show that at least when it comes to supporting students with difficulties in the FSL classroom, a teacher's personal experience with disability could make a difference in how the student is viewed by the teacher. Extending the findings of Pattniak (1997), who found that teacher candidates who lacked personal experience with individuals from different race or ethnic backgrounds had more negative views of students from race backgrounds different from their own, it appears that this study shows some limited evidence of a similar trend when the different culture is represented as "difficulty."

Further, in the optional section for additional narrative comments, six of the eleven candidates who self-reported changes in their perceptions of students with learning difficulties indicated that their perceptions changed because of positive experiences with students with learning difficulties. Though some participants' comments still questioned whether students with learning difficulties could benefit from the FSL experience, it seems that the teacher candidates were open to having these ideas challenged through experience in the classroom. Further, participants who had longer practica in FSL classrooms indicated that they more strongly believed that the strategies needed to support students with LD were compatible with their teaching styles. This was somewhat contradictory to the results of the first questionnaire, which showed that participants with prior FSL teacher experience had lower levels of agreement with certain statements about the presence of students with LD in the FSL classroom, so it could be that the seemingly open views will change over time. This would be an interesting consideration in future research.

As it pertained to the influences on the participants' perceptions of the student populations, there was some confirmation of trends in prior research that have revealed that teacher candidates' views on issues are largely unmoved by outside forces, such as research, the opinion of others, or coursework (e.g., Garmon, 2004; Peacock, 2001). However, in open-ended comments, several participants did report that coursework in their FSL programs did have an influence on their views, but the current instrument did not allow for the determination of which participants attended which program. Such consideration may be beneficial in future research, to determine if coursework that focuses on the educational experience of these populations in the FSL classroom actually goes against the trend in the larger research corpus. Because these student populations have been attached to popular myths about their potential for success in the FSL classroom, it could be that coursework that directly addresses those myths may be of greater benefit than other types of coursework.

Returning to critical theory, the last consideration for this research is the construct of access and benefit. The actions of a teacher in a classroom setting can consciously and subconsciously replicate power structures that serve to affirm and perpetuate the status quo and keep certain students from gaining from the learning experience (Willis et al., 2008). In this research, the results do point to the potential for disadvantage of students with learning difficulties, as it pertains to the FSL experience. Though the participants held largely positive views about the student populations' rights to access the FSL curriculum, the participants did agree that there were times when students with learning difficulties should be exempt from the FSL requirement. In exempting students from FSL, students with learning difficulties can be placed at a disadvantage for employment or later educational opportunities, an action that could further promote the idea that individuals with disabilities are 'lacking'.

Thus, there are differences perceptions of the right to access FSL, and it would be worthwhile to turn to more qualitative sources to see if it might be possible to explain why such a difference exists. The construct of benefit was a more indirect focus in this research, as measured through the questions about teaching methods and supports needed to help the student populations, so conclusions are difficult to draw. It would be useful to more directly address teacher candidates' perceptions of the potential for benefit of FSL study by this student population in later work.

Nonetheless, this study has revealed that from the start of their teaching careers, there are some pre-service candidates who will be positioning students with learning difficulties at disadvantage, making it that much harder for this student population to find success. Perhaps there would be value in ensuring that pre-service candidates had access to certain experiences on their path to their own classrooms, so as to mitigate some of these negatives.

\section{REFERENCES}

[1] Ajzen, I. (1991). Attitudes, personality and behaviour. Milton Keynes: Open University.

[2] Arnett, K. (2010). Scaffolding inclusion in a grade 8 core French classroom: An exploratory case study. The Canadian Modern Language Review, 66, 4, 603-628.

[3] Arnett, K. (2008). Exploring the use of student perspectives to inform topics in teacher education: Issues in creating an inclusive core French classroom. Canadian Journal of Applied Linguistics, 11, 1, 63-81.

[4] Arnett, K. (2003). Teacher adaptations in core French: A case study of one grade 9 class. The Canadian Modern Language Review, 60, 2, 173-198.

[5] Arnett, K. \& Mady, C. (2010). A critically conscious examination of special education within FSL and FSL teacher education programs. The Canadian Journal of Applied Linguistics, 13, 1, 19-36. 
[6] Arnett, K. \& Turnbull, M. (2007). Teacher beliefs in second and foreign language teaching: A state of the art review. In, H.J. Siskin (Ed.), AAUSC 2007: From thought to action: Exploring beliefs and outcomes in the foreign language program, (pp. 928). Boston: Heinle \& Heinle.

[7] Bartolomé, L. I. (2004). Critical pedagogy and teacher education: Radicalizing prospective teachers. Teacher Education Quarterly, 31(1), 97-122.

[8] Calman, R. D. \& I. Daniel. (1998). A board's eye view of core French: The North York Board of Education. In S. Lapkin (Ed.), French second language education in Canada: Empirical studies (pp. 281-323). Toronto, ON: University of Toronto Press.

[9] Friere, P. (1998). Teachers as cultural workers. Boulder, CO: Westview Press.

[10] Garmon, (2004). Changing preservice teachers' attitudes/beliefs about diversity: What are the critical factors? Journal of Teacher Education, 55(3), 201-213.

[11] Garmon, (2005). Six key factors for changing preservice teachers' attitudes/beliefs about diversity: What are the critical factors? Educational Studies, 38(3), 275-286.

[12] Genesee, F. (2007). French immersion and at-risk students: A review of research evidence. The Canadian Modern Language Review, 63(5), 655-688.

[13] Hutchinson, N. \& Martin, A. (2012). Inclusive classrooms in Ontario schools. Toronto: Pearson Education Canada.

[14] Johnson, K.E. (1999). Understanding language teaching: Reasoning in action. Toronto: Heinle \& Heinle.

[15] Jordan, A. (2007). Introduction to inclusive education. Mississauga, ON: Wiley.

[16] Jordan, A., Lindsay, L., \& Stanovich, P. (1997). Classroom teachers' instructional interactions with students who are exceptional, at risk, and typically achieving. Remedial and Special Education, 18 (2), 82-93.

[17] Kennedy, C. \& Kennedy, J. (1996). Teacher attitudes and change implementation. System, 24(3), 351-360.

[18] Lapkin, S., A. MacFarlane, and L. Vandergrift. (2006, September). Teaching FSL in Canada: Teachers'perspectives. Plenary presented at the Congrès 2006 of ACPI, ACPLS, and APFS. Saskatoon, Saskatchewan, Canada.

[19] Lortie, D. (1975). School teacher: A sociological study. Chicago: University of Chicago Press.

[20] Mady, C. \& Arnett, K. (2009). Inclusion in French Immersion in Canada: One parent's perspective. Exceptionality Education International. 19, 2, 37-49.

[21] Mannavarayan, J.M. (2002). The French immersion debate: French for all or all for French? Calgary, Alberta, Canada: Detselig Enterprises.

[22] Mastropieri, M.A. \& Scruggs, T.E. (2010). The inclusive classroom: Strategies for effective differentiated instruction. Upper Saddle River, NJ: Merrill.

[23] Mills, C. \& Ballantyne, J. (2008). Pre-service teachers' dispositions towards diversity: Arguing for a developmental hierarchy of change. Teaching and Teacher Education, 26, 447-454.

[24] Pajares, M.F. (1992). Teachers' beliefs and educational research: Cleaning up a messy construct. Review of Educational Research, 62(3), 308-332.

[25] Pattniak, J. (1997). Cultural stereotypes and preservice education: Moving beyond our biases. Equity and Excellence in Education, 30, 40-50.

[26] Peacock, M. (2001). Pre-service ESL teachers' beliefs about second language learning: A longitudinal study. System, 29, 177195.

[27] Statistics Canada (2006). Women in teaching related positions, Canada, 1996 and 2006. Available: http://www.statcan.gc.ca/pub/89-503-x/2010001/article/11542/tbl/tbl013-eng.htm.

[28] Willis, A. I., M. Montavon, H. Hall, C. Hunter, L. Burke, \& A. Herrera. (2008). On critically conscious research: Approaches to language and literacy research. New York: Teachers College Press.

[29] Wise, N. (2011). Access to special education for exceptional students in French immersion programs: An equity issue. The Canadian Journal of Applied Linguistics, 14(2), 177-193.

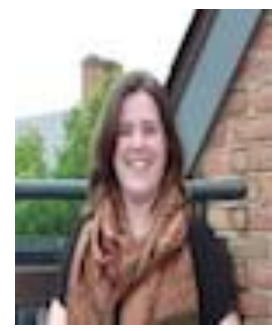

Katy Arnett, holds a B.A. in foreign language (French) from St. Mary's College of Maryland, St. Mary's City, Maryland, USA (2000), and both a M.A. (2001) and Ph.D. (2004) in second language education from the Ontario Institute for Studies in Education of the University of Toronto, Toronto, Ontario, Canada. Additionally, she is a certified teacher of French, Grades 7-12, for the state of Maryland.

She is currently associate professor \& chair of Educational Studies at St. Mary's College of Maryland, USA. She worked for several years as a teacher of French in Grades 8-12 before moving into teacher education. Among other venues, her research has appeared in the Canadian Journal of Applied Linguistics, the Canadian Modern Language Review, and Exceptionality Education International. With Callie Mady, she coedited and contributed to the recent volume, Minority populations in Canadian Second Language Education (Bristol, United Kingdom, Multilingual Matters 2013). Her research interests focus broadly on issues related to the support and/or inclusion of students with specialized learning needs within a particular context, including students with learning difficulties in French Second Language classrooms in Canada and more recently, newcomer students to English-speaking school systems.

Dr. Arnett is a member of several professional associations, including the American and Canadian Associations of Applied Linguistics. In 2012-2013, she was named a Fulbright Scholar, allowing her to pursue new research in her areas of specialty from the base of the Second Language Research Institute of Canada at the University of New Brunswick. 


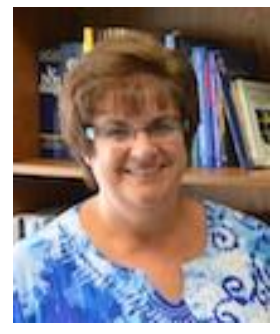

Callie Mady received her Bachelor of Arts at McGill University in Montréal, Québec, Canada in 1987, her Bachelor of Education from Brock University in Hamilton, Ontario, Canada in 1988, her Masters of Arts in 2003 and her Doctor of Philosophy in 2006 from the Ontario Institute for Studies in Education of the University of Toronto, Toronto, Ontario, Canada. Her graduate degrees focused on second language education.

Callie is currently an associate professor in the Schulich School of Education at Nipissing University, North Bay, Ontario, Canada. Previously, she taught second languages at the elementary and secondary levels. Among her various publications, she co-edited a book with Katy Arnett entitled Minority Populations in Canadian Second Language Education (Bristol, United Kingdom: Multilingual Matters, 2013). Her research interests include French as a second language education and multilingual language acquisition. In particular, her research focuses on minority populations in those areas - immigrants and students with learning difficulties.

Dr. Mady is currently serving as President of the Canadian Association of Applied Linguistics and has been actively involved in the planning of its annual conference for the past several years.

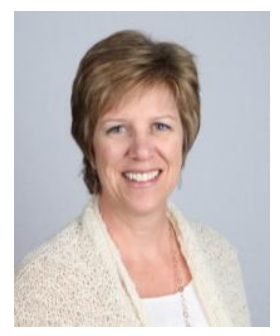

Lin Muilenburg earned a B.S. in secondary education for biology and general science from The Pennsylvania State University in 1985. She was awarded an M.A. in instructional systems development by the University of Maryland Baltimore County in 1996. Conferral of her Ph.D. in instructional design and development by the University of South Alabama occurred in 2008.

She is an associate professor in the Department of Educational Studies at St. Mary's College of Maryland in St. Mary's City, MD, USA. Previous work included teaching secondary science and mathematics, providing job-embedded staff development to educators, and consulting to improve training programs for corporations, non-profits, and educational institutions. Her research interests are varied and include mobile and elearning, instructional technology, and education policy. She is the co-editor of the Handbook of Mobile Learning (New York, NY: Routledge, 2013).

Dr. Muilenburg served as a program committee member for the Classroom, Ubiquitous and Mobile Technologies Enhanced Learning sub-conference of the International Conference on Computers in Education 2013, in Bali, Indonesia. She is a manuscript reviewer for the International Journal of Teaching and Learning in Higher Education, Computers and Education, the International Journal of Mentoring and Coaching in Education, and the MERLOT Journal of Online Learning and Teaching. 